\title{
Review on Domestic English Writing Research in Senior One ${ }^{1}$
}

\author{
Nana Jing \\ Chongqing Normal University, Chongqing 401331, China \\ Yun Zhang \\ Chongqing No.7 High School, Chongqing 400030, China \\ Qiang Huang \\ Chongqing Qingmuguan Middle School, Chongqing 401334, China \\ Can Wang \\ Chongqing No.7 High School, Chongqing 400030, China
}

\begin{abstract}
English writing in senior one. Through categorization and analysis of related studies from 1999-2018 on CNKI, the paper finds out that existing studies concerned with English writing in senior one still show the tendency of being a bit fragmented and there is still gap in more comprehensive and deep studies; on the other hand, studies carried out more focus on the descriptive aspects of English writing or application of a typical theory in certain students group. Taking into consideration previous research efforts, suggestions for future research are as follows. To begin with, more researchers at different levels should be involved in the study, especially strengthening the collaboration between researchers, college teachers and front-line English teachers in senior high school; besides, research should be more based on scientific ground, rather than purely on empirical experiences; in addition, a large sample based research in status quo should not be left out.
\end{abstract}

Index Terms - review, research, domestic English writing, senior one

\section{INTRODUCTION}

Writing is a reflection of students' comprehensive language skills, which requires the integration of students' observation, thinking, imagination, creativity, and expression and it is one of the most difficult part to teach and to learn. $\mathrm{Xu}$ (2009) points out that writing teaching is an important part of high school English teaching. It runs through the whole process of English teaching and is always accompanied by the teaching of linguistic knowledge such as vocabulary and grammar. National English Curriculum Standards for Senior High School ${ }^{2}$ describes the English writing skills with the can do statement and quantifies the requirements that the eight-level goal should be completed in high school phase. Students are required to be able to write coherent and structured essays, be able to write according to stylistic norms, be fluent in expressions, be able to write abstracts, reports, notices, and official letters in English, and be able to explain personal point of view, comment on others' opinions in an appropriate style and so on. In the College Entrance Examination, English writing occupies a considerable proportion (25 points in the national test).

However, the truth is that with the rapid advancement of English teaching reform and the full implementation of new curriculum standards, students' listening and speaking abilities have been greatly improved, but the ability to read and write is still not that satisfactory. It is high time we made efforts in improving students' writing ability. Senior one marks the transitional stage from junior middle school to senior middle school, which is of vital students' importance. Therefore, teachers should pay attention to writing teaching from the beginning of the high school and make writing training throughout the entire period of high school English teaching. This paper, taking English writing as the focus, tries to make a review of how English writing research moves in senior one to illustrate how we are teaching English writing in senior one domestically.

\section{RESEARCH PROCESS}

\section{A. Data Source}

This paper focuses on English writing in senior one and the collected data are from published materials on website.

\footnotetext{
1 Senior one in our paper refers to grade one in senior high school.

${ }^{2}$ http://www.zxxk.com/soft/7274732.html
} 
To be more specific, we download all research papers from CNKI, including papers, M.A thesis and possibly doctoral dissertation. ${ }^{3}$ The two key words are senior one plus English writing.

\section{B. Research Questions}

Our review focus on answering the following two key questions:

a. How does English writing in senior one proceed domestically? And what is the possible research trend?

b. what should the future research orientations be?

\section{ANALYSIS OF DATA}

\section{A. Overview}

When the two key words senior one plus English writing are put in the search column on CNKI, we find that research concerned with English writing began from the year 1999; that is to say, more than 20 years have passed. Then, we sort out research papers yearly. Altogether, there are 79 papers. Through reading and preliminary analysis, we delete those which are not that closely related to the chosen topic, and finally lock 51 papers in all, with the distribution in each year is shown in table (1):

TABLE 1

GENERAL DISTRIBUTION OF RESEARCH PAPERS ${ }^{4}$

\begin{tabular}{|l|l|l|l|l|l|l|}
\hline 2018 & 2017 & 2016 & 2015 & 2014 & 2013 & 2012 \\
\hline 1 & 5 & 7 & 7 & 5 & 4 & 7 \\
\hline 2011 & 2010 & 2009 & 2008 & 2007 & 2006 & $1999-2005$ \\
\hline 4 & 4 & 2 & 0 & 3 & 1 & 1 \\
\hline
\end{tabular}

Generally speaking, research in English writing in senior one is on an increase (with papers in 2008 expected to be on the rise). We can infer that more and more concern has been directed toward the given topic, which goes in line with the emphasis on English teaching at home. We sort out all the papers. Based on group discussion, we try to categorize all of them according to research concern (or research topics) and research methods, which are shown in the two sections followed.

\section{B. Research Concern}

To well display previous researchers' research concern, we summarize the main topics covered. To be more specific, we find that previous research mainly centers on the following 9 common topics: 1) error analysis in students' writing (Yan 1999, Jiang 2010, Li 2013, Mao 2016, Li 2016). For instance, Li (2016) explores students' errors in English writing through a case study of 82 sample writings and analyze the she also tries to explain the underlying reasons. Jiang (2010) takes two teaching classes in senior one as an example, and collects 10 pieces of writing of each students for error analysis. She finds out that errors in their writing can be roughly divided into three types: vocabulary level errors. Syntactic level errors and textual errors and provides rather detailed analysis for each type with typical examples and explanations; 2) application of certain teaching methods/approaches in senior one English writing, which is mostly seen in the master thesis (Li 2006, Zhang 2007, Dong \&Ye 2007, Xu 2009, Qiu 2009, Zhuang 2014, Li 2017, etc.). Li (2006) in her master thesis carries out a study of task-based language teaching in English writing. Zhang (2007) explores the application of cooperative writing. Xu (2009) argues for the use of stratified method in writing taking into consideration students' differences and summarize some principles and specific strategies that could be employed. Qiu (2009) explores the process approach; Li (2017) takes two senior one parallel classes Jiyuan senior high school of Henan province and proves that mind-mapping based interactive model not only improves students' interest in English writing but also improves their writing ability through analysis of data; 3) analysis of status quo of English writing and possible countermeasures (Zhang 2011, Li 2014, Ma 2014, Chen \& Guo 2015, Zhou 2016, Yang \& Li 2018). Zhang (2011) takes the four senior one classes in Xiangtan No.3 middle school as an example and finds out some problems like students' lacking in motivation, shrinking back in face of writing, poor in English basics, poor in teachers' effective guidance and proper feedback on basis of questionnaire and interview; 4) specific ways to improve students' writing ability, which usually characterizes works of front-line teacher researchers (Li 2011, Yang 2012, Tang 2015, Chen 2015). For example, Li (2011) advocates improving students' writing through teachers' arrangement of material, textbook-based practice, strengthening of writing techniques and proper feedback on personal experience. Tang (2015) argues that English writing in senior one requires that students provide information through written text or graphics and briefly describe character or event. To meet such typical requirements, Tang outlines detailed measures in training students' writing ability, such as improving students' basic English language proficiency, reciting recommended samples, forming the habit of keeping journals and so on; 5) exploration of connecting technological benefits with English

\footnotetext{
${ }^{3}$ CNKI refers to the National Knowledge Infrastructure (China) originally and was later interpreted as China National Knowledge Internet. Based on the "China Knowledge Resource Bank", It is the world's largest Chinese knowledge portal, featured by a continuously updated Chinese journals (partially translated from https://baike.sogou.com/v3347259.htm? fromTitle=cnki).

${ }^{4}$ Here research paper includes all research results on CNKI, including M.A thesis, possibly doctoral dissertation and conference papers (accessed in April).
} 
writing (Geng \& Zhou 2012, Tan 2017). Geng \& Zhou (2012) tries to explore how QQ and related functions could be incorporated into the writing process of students. Tan (2017) takes one typical writing task to illustrate how the auto grading system-Pigaiwang (www.pigai.org)can be used in students' writing to stimulate students' motivation, create a harmonious competitive atmosphere, cultivate students' good writing habits, and improve students' writing skills; 6) the transition of writing from junior three to senior one ( $\mathrm{Wu} 2017) . \mathrm{Wu}$ (2017) points out the fact that writing in junior three and senior one are different in writing requirements, in textbook materials and in given topics, and therefore, teachers should focus on guidance in writing techniques and cultivation of students' interest; 7) full exploration of textbook in writing (Jiang 2012, Ju 2017). Ju (2017) argues that senior one English teachers should try best to make use of textbook materials and explore the strategies of English writing teaching in senior one from two aspects of controlled writing mode and open writing mode; 8) regional differences in writing (Xu 2016). Xu (2016) pays attention to students in rural areas and argues that teachers in senior one should embark on vocabulary and grammar consolidation, practical guidance and interest cultivation to improve their writing taking into consideration their poor English proficiency; 9) writing assessment (Zhang 2016, Ma 2016, Yue 2017). Zhang (2016) takes two teaching classes in Chongqing Fengjie middle school as the research object and tries to prove the effectiveness of a comprehensive assessment system of self-assessment, peer assessment and teacher's assessment. Ma (2016) in her master thesis studies teacher's written corrective feedback. The study takes students of No.8 senior high school in Yining City as the research subjects and find out that teacher's written corrective feedback is helpful to students' English writing performance, and the direct feedback is more helpful to the improvement of students' performance than the indirect feedback. Yue (2017) in his master thesis proves that senior one students' English writing ability and self-reflection have been improved a lot under the guidance of process-oriented approach and portfolio-assisted assessment.

\section{Research Methods}

As far as research methods are concerned, roughly speaking previous research mainly employs the following two types of methods: 1) empirical studies based on personal experience (Yan 1999, Chen 2007, Song 2010, Zhu 2010, Qiang 2011, Yin \& Zhuang 2011, Zhang 2014, Shi 2015). For example, Yan (1999) tries to collect and categorize students' errors in writing task and proposes the suggestions of recitation, self-check and encouragement for improving their writing. Chen (2007) takes Unit 7 cultural relics as an example. She shares her own experience in carrying out English writing in this unit and puts forward the idea that interest and reading input are important in writing; Dong \& Ye (2007) first point out students' problems in writing and proposes the methods of modelling writing (sentences) and the use of visual-audio method in writing; Zhu (2010) through personal teaching experience, stresses students' interest, appropriate teaching method, students' habit and evaluative methods are important factors influencing their writing; 2) combination of the qualitative and quantitative methods, which is typical of the master thesis concerned with application of certain approaches in last section (Li 2006, Zhu 2012, Zhang 2007, Qiu 2009, Tian 2010, Shen 2012, Li 2013, Lv 2013, Wang 2013, Qiu 2013, Yan 2015, Xu 2015, Fan 2015, Zhang 2016). They try to explore the how each of the following teaching methods such as task-based teaching, cooperative method, process method, reading-writing integration approach, process-genre approach, process-product approach, cooperative learning theory, scaffolding instruction and lexical approach gains more favorable result in senior one English writing compared with the traditional approach. They mainly employ questionnaire and analysis of the experimental results in the research; to be more specific, they usually divide the research participants (less than 200) of one sample middle school into experimental class and the control class and compare the different results and search for possible explanations.

\section{CONCLUSION}

Previous researchers domestically have made great efforts to explore English writing in senior one and their achievements can be summarized as follows:

As far as research concern is concerned, existing studies already cover a wide range of topics such as error analysis, status quo analysis and countermeasures, application of certain teaching methods in writing, ways to improve students' writing ability, exploration of connecting technological benefits with writing, which not only reflect those earlier research concern but also correspondence with change of time. For example, connecting technological benefits with writing practice, such as the use of QQ and the auto scoring system.

Concerning research methods, existing studies either resort to the empirical study on personal experience or an experimental study taking students in one typical school as the participants. Those who apply empirical study are front-line teachers who try to summarize some experiences through daily teaching and observation and their papers center on pointing out mistakes and problems in students' writing and propose possible suggestions. Those who employ the experimental method are mainly M.A. students. They usually choose two or more senior classes in one typical senior high school as the subjects, and then they try to prove the effectiveness of a certain existing teaching method by comparing it with traditional teaching method.

It should be noted that this paper does have limitations and weaknesses. For instance, the data for analysis are all from the largest database CNKI, and there is great possibility that papers, articles or books related to English writing in senior one also exist elsewhere and therefore, more wide and accurate data collection process is needed for a review study in the future; on the other hand, our standard for classifying previous research according to research topics and 
research method is not scientifically based, rather, it is based on observation and discussion in our group, which may also be not that accurate and requires attention.

\section{SugGestions For Future Research}

Senior one can be an important transitional stage in students' learning life and English writing in senior one can be quite different from that in junior middle school since it marks the very beginning of higher requirements for writing in College Entrance Exam (Chinese gaokao), which deserves our special attention. Up to now, there is still large space in further exploring English writing in senior one. Here are our suggestions.

To begin with, more researchers should be involved in the current study; it is especially critical to strengthen the collaboration between researchers, college teachers and front-line English teachers in senior one. As has been pointed out, there is hardly any doctoral candidate or university researchers involved in previous studies in senior one English writing. No doubt that researchers at different levels contribute somewhat differently, which makes it possible to initiate studies of different angles and may even contribute to deep and more comprehensive studies;

Secondly, research should be more based more on scientific ground, rather than only empirical experiences or application of a certain method in practice. Up to now, application of scientific methods is largely seen in those college students whose research orientation is possibly English teaching in middle or high school. As a result, they employ a certain approach different from the traditional one and all prove that the new approaches, no matter the task-based approach, the cooperative approach or the process approach and others, have instant desirable results. However, many questions remain unsolved: which approach is the more suitable one? What is the difference in the benefits of each approach? What will happen if the research subjects are replaced? What will happen if there is a longitudinal study? Educational background in senior one may be very different from that abroad or in university, which requires our studies to be more well directed, deep, longitudinal and systematic;

There should be a much deeper and wider investigation into the status quo in senior one English writing. As is pointed out in the analysis part, concerning all research papers we have collected up to now, there is still drawbacks in taking status quo analysis as the research concern. Those who do only take a rather small sample of several classes in one middle school for investigation, which may not cover the whole situation. In addition, with information technology more immersed in everyone's life and in English teaching at all level, it is high time teachers faced the reality and tried best to bring into English writing classroom the technological benefits, not only QQ (mentioned in the analysis part) and therefore more research in this aspect should be carried out in future.

\section{ACKNOWLEDGEMENTS}

The project (FAR201702004) partially described in this paper is supported by the Fund for Assessment Research in Foreign Language Education. We are indebted to the members who participated in this project and to experts who guided the research.

\section{REFERENCES $^{5}$}

[1] Chen, J. (2007). Reflections from a senior one English writing class. Foreign Language Teaching in Schools 7, 13-17.

[2] Chen K. (2015). An empirical study of discourse recitation in promoting senior one students' English writing. M.A. thesis, Hunan Normal University.

[3] Chen, X.Z. \& Guo, W.G. (2015). On status quo of senior one English writing: A case study of P County in Shanxi Province. Course Education Research 28, 99.

[4] Dong, H. \& Ye, D.X. (2007). Problem analysis and practice exploration in senior one English writing teaching. Modern Primary and Secondary Education 9, 41-43.

[5] Fan, Y.L. (2015). Application of scaffolding approach in senior one English writing teaching. M.A. thesis, Inner Mongolia Normal University.

[6] Geng, H. \& Zhou, X. (2012). Application of QQ software in senior one English writing teaching. The Chinese Journal of ICT in Education 4, 57-60.

[7] Jiang, J.W. (2012). Excavating textbook resources to improve senior one English writing teaching. Testing and Evaluation 4, 26.

[8] Jiang, Y. (2010). Errors analysis in senior one English writing. M.A. thesis, Northeast Normal University.

[9] Ju, C.M. (2017). Excavating textbook resources to Improve the effectiveness of senior one English writing teaching-Taking Oxford high school English teaching materials as an example. English Teachers 17. 23, 104-108.

[10] Li, H.J. (2013). Research on the influence of process writing method on the English writing ability of senior one students. M.A. thesis, Capital Normal University.

[11] Li, L. (2011). On strengthening the English writing ability of senior one students. Exam Weekly 68, 117.

[12] Li, M. (2014). Strategies in senior one English writing teaching. English Journal for Middle School Students 5, 7.

[13] Li, P. (2014). Grammar instruction in senior one classroom writing teaching. Exam Weekly 1, 93-94.

[14] Li, P.L. (2006). Application of task-based language teaching in senior one English writing. M.A. thesis, Northwest Normal University.

\footnotetext{
${ }^{5}$ Chinese references are translated by the authors and comments are welcomed.
} 
[15] Li, X.N. (2016). Error analysis in senior one students' English writing. M.A. thesis, Central China Normal University.

[16] Li, X.Y. (2017). An empirical study on the mind-mapping-based interactive teaching mode in senior one English writing classroom. M.A. thesis, Central China Normal University.

[17] Li, Y. A. (2013). Case study of errors in senior one English writing. Exam Weekly 49, 82-83.

[18] Lv, J.E. (2013). Application of the process-product approach in senior one English writing teaching. M.A. thesis, Inner Mongolia Normal University, 2013.

[19] Ma, F. (2014). Status quo and countermeasure in senior one English writing. M.A. thesis, Henan Normal University.

[20] Ma, X. (2016). Research on the effects of different types of teachers' written corrective feedback on senior one English writing. M.A. thesis, Xinjiang Normal University.

[21] Mao, L.T. (2016). Error analysis of senior one English writing. M.A. thesis, Central China Normal University.

[22] Qiang, Q.J. (2011). On strategy in senior students' English Writing. New University Entrance Examination 10, 44-46.

[23] Qiu, L.L. (2009). The application of process teaching approach in improving the writing efficiency of senior one students. M.A. thesis, Sichuan Normal University.

[24] Qiu, X.J. (2014). Application of lexical chunks in senior one English writing. M.A. thesis, Sichuan Normal University.

[25] Shen, R. (2012) Application of process genre approach in improving the English writing ability of senior one students. M.A. thesis, Chongqing Normal University.

[26] Shi, X.J. (2015). On cooperative learning in senior one English writing teaching. Campus English 32, 99.

[27] Song, L. (2010). How to improve the English writing ability of senior one students. Youth Diary 9, 31.

[28] Tan, S.F. (2017). The application of Pigaiwang (www.pigai.org) in senior high school English writing- Taking the lesson Giving Advice in senior one as an example. Educational Information Technology 22, 47-49.

[29] Tang, Y.J. (2015). Strategies in senior one English writing training. Teaching Reference in Middle School 10, 47-48.

[30] Tian, L. (2010). An experimental study on improving English writing ability of senior students through reading-writing integration approach. M.A. thesis, Northeast Normal University.

[31] Wang, X \& Liu, S. (2012). An inquiry into senior one English writing teaching under the new curriculum standards. China Education Innovation Herald 6, 14.

[32] Wang, Y. (2013). Application of cooperative learning in senior one English writing teaching. M.A. thesis, Shanghai Normal University.

[33] Wu, G.F. (2017). On the transition of English writing from junior middle to senior high. English Journal for Middle School Students 8, 17.

[34] Xu, T.W. (2016). A preliminary study of English writing of senior one students in rural high school. Life Education 16, 48-49.

[35] Xu, X.H. (2009). A preliminary study of stratified teaching in senior one English writing. Exam Weekly 47, 113-114.

[36] Xu, X.W. (2015). Application of scaffolding approach in senior one English writing teaching. M.A. thesis, Sichuan Normal University.

[37] Yan, J. (1999). How to treat errors in English writing in senior students in the first grade. Journal of Beijing Institute of Education 2, 81-82.

[38] Yan, J. (2015). The influence of reading and writing approach on English writing performance of senior one students. M.A. thesis, Soochow University.

[39] Yang, D.C. (2012). On effective English writing teaching in senior one. New West Z3, 217+219.

[40] Yang X.L \& Li, F.F. (2018). On the current situation of English writing and analysis of effective strategies. Good Parents 3,164.

[41] Yang, X.W. (2016). Discussion on the teaching methods in senior one English writing. New Course 8, 7.

[42] Yin, X.L \& Zhuang, W.Y. (2011). Study on English writing training model for senior one students. Exam Weekly 92, $101-103$.

[43] Yue, L.J. (2017). Application of process writing approach and portfolio evaluation in senior one English writing teaching. M.A. thesis, Sichuan Normal University.

[44] Zhang, F.L. (2016). Research on self-evaluation, peer assessment and teacher evaluation in senior one English writing- Taking Fengjie Middle School as an example. The Guide of Science \& Education 8, 93-94+109.

[45] Zhang, L.H. (2014). Discussion on improving the English writing ability of senior one students. Education and Teaching Forum 34,102.

[46] Zhang, M. (2016). Application of lexical approach in senior one English writing. M.A. thesis, Shanxi Normal University.

[47] Zhang, Y. (2007). The Application of cooperative writing in senior one English writing teaching. M.A. thesis, Inner Mongolia Normal University, 2007.

[48] Zhang, Y.Y. (2011). Status quo and countermeasures of English writing teaching in senior one. M.A. thesis, Hunan University of Science and Technology.

[49] Zhu, H.B. (2010). On English writing in senior one. English Journal for Middle School Students 25, 30-31.

[50] Zhu, J.Y. (2012). Application of task-based approach in senior one English writing. M.A. thesis, Chongqing Normal University.

Nana Jing received her master degree in linguistics from Guangdong University of Foreign Studies in 2013. She is currently lecturer on College of Foreign Languages and Literatures, Chongqing Normal University, Chongqing, China. Her main research interest is syntax and language education.

Yun Zhang was born in Chongqing, China in 1980. He received his bachelor degree from Chongqing Normal University in 2002.

He is currently a teacher in Chongqing No.7 High School, Chongqing, China. His research interests include psycholinguistics and American literature. 
Qiang Huang was born in Chongqing, China in 1985. He received his bachelor degree from Chongqing College of Arts and Sciences, China in 2008.

He is currently a teacher in Qingmuguan middle school. His research interests include teaching and management.

Can Wang was born in Chongqing, China in 1989. She received her master degree in linguistics and applied linguistics from Chongqing University in 2015.

She is currently a teacher in Chongqing No.7 High School, Chongqing, China. Her research interests include linguistics and American literature. 